\title{
Androgens sensitise mice to glucocorticoid-induced insulin resistance and fat accumulation
}

\author{
Sylvia J. Gasparini ${ }^{1}$ • Michael M. Swarbrick ${ }^{1}$ - Sarah Kim ${ }^{1}$ • Lee J. Thai ${ }^{1} \cdot$ Holger Henneicke $^{1,2,3,4} \cdot$ Lauryn L. Cavanagh $^{1}$ • \\ Jinwen $\mathrm{Tu}^{1} \cdot$ Marie-Christin Weber ${ }^{1,5} \cdot$ Hong Zhou $^{1,6} \cdot$ Markus J. Seibel ${ }^{1,6}$
}

Received: 12 March 2019 / Accepted: 4 April 2019 / Published online: 16 May 2019

(C) Springer-Verlag GmbH Germany, part of Springer Nature 2019

\begin{abstract}
Aims/hypothesis Chronic glucocorticoid therapy causes insulin resistance, dyslipidaemia, abnormal fat accumulation, loss of muscle mass and osteoporosis. Here we describe a hitherto unknown sexual dimorphism in the metabolic response to chronic glucocorticoid exposure in mice. This led us to investigate whether glucocorticoid-induced insulin resistance and obesity were dependent on sex hormones.

Methods Male and female CD1 mice were treated for 4 weeks with supraphysiological doses ( $250 \mu \mathrm{g} / \mathrm{day})$ of corticosterone, the main glucocorticoid in rodents, or equivalent volume of vehicle (drinking water without corticosterone). To investigate the effects of sex hormones, a separate group of mice were either orchidectomised or ovariectomised prior to corticosterone treatment, with or without dihydrotestosterone replacement. Body composition was determined before and after corticosterone treatment, and insulin tolerance was assessed after 7 and 28 days of treatment. Adipocyte morphology was assessed in white and brown adipose tissues by immunohistochemistry, and fasting serum concentrations of NEFA, triacylglycerols, total cholesterol and free glycerol were measured using colorimetric assays. Obesity- and diabetes-related hormones were measured using multiplex assays, and RNA and protein expression in adipose tissues were measured by RT-PCR and immunoblotting, respectively.

Results Chronic corticosterone treatment led to insulin resistance, fasting hyperinsulinaemia, increased adiposity and dyslipidaemia in male, but not female mice. In males, orchidectomy improved baseline insulin sensitivity and attenuated corticosterone-induced insulin resistance, but did not prevent fat accumulation. In androgen-deficient mice (orchidectomised males, and intact and ovariectomised females) treated with dihydrotestosterone, corticosterone treatment led to insulin resistance and dyslipidaemia. In brown adipose tissue, androgens were required for corticosterone-induced intracellular lipid accumulation ('whitening'), and dihydrotestosterone specifically exacerbated corticosterone-induced accumulation of white adipose tissue by increasing adipocyte hypertrophy. Androgens also suppressed circulating adiponectin concentrations, but corticosterone-induced insulin resistance did not involve additional suppression of adiponectin levels. In white adipose tissue, androgens were required for induction of the glucocorticoid target gene Gilz (also known as $T s c 22 d 3$ ) by corticosterone.
\end{abstract}

Sylvia J. Gasparini and Michael M. Swarbrick contributed equally to this work.

Electronic supplementary material The online version of this article (https://doi.org/10.1007/s00125-019-4887-0) contains peer-reviewed but unedited supplementary material, which is available to authorised users.

Markus J. Seibel

markus.seibel@sydney.edu.au

1 Bone Research Program, ANZAC Research Institute, The University of Sydney, Gate 3, Hospital Road, Concord, NSW 2139, Australia

2 Department of Medicine III, Technische Universität Dresden Medical Center, Dresden, Germany

3 Center for Healthy Aging, Technische Universität Dresden Medical Center, Dresden, Germany
4 Center for Regenerative Therapies Dresden, Technische Universität Dresden, Dresden, Germany

5 Department of Rheumatology and Clinical Immunology, Charité University Hospital, Berlin, Germany

6 Concord Medical School, The University of Sydney, Sydney, Australia 


\section{Research in context}

\section{What is already known about this subject?}

- Chronic glucocorticoid treatment is accompanied by detrimental metabolic outcomes, including insulin resistance, hyperinsulinaemia, central obesity and osteoporosis

- The metabolic response to chronic stress is sexually dimorphic, with stress-induced metabolic syndrome being more prevalent in men than in women

- Acute glucocorticoid treatment produces sexually dimorphic patterns of gene expression in rat liver, related to cell death, differentiation and inflammation

\section{What is the key question?}

- Why do glucocorticoids induce severe insulin resistance and obesity in male but not female mice?

\section{What are the new findings?}

- Chronic corticosterone treatment produced insulin resistance, fasting hyperinsulinaemia, obesity and dyslipidaemia in male, but not female mice. In males, these effects were largely prevented by orchidectomy and in androgen-deficient mice (orchidectomised males, and intact and ovariectomised females), dihydrotestosterone treatment augmented glucocorticoid-induced insulin resistance and dyslipidaemia

- Androgens were required for corticosterone-induced lipid accumulation ('whitening') in brown adipose tissue, and exacerbated accumulation of white fat following corticosterone treatment

- Gene expression analysis revealed that androgens sensitised white adipose tissue to the transcriptional effects of glucocorticoid treatment

How might this impact on clinical practice in the foreseeable future?

- Men and hyperandrogenic women should be closely monitored for prevention and management of the metabolic side effects associated with long-term glucocorticoid treatment

Conclusions/interpretation In mice, androgens potentiate the development of insulin resistance, fat accumulation and brown adipose tissue whitening following chronic glucocorticoid treatment.

Keywords Adipose tissue - Androgens · Glucocorticoid · Insulin resistance

Abbreviations
$\begin{array}{ll}\text { BAT } & \text { Brown adipose tissue } \\ \text { DHT } & \text { Dihydrotestosterone } \\ \text { DXA } & \text { Dual-energy x-ray absorptiometry } \\ \text { GIP } & \text { Gastric inhibitory peptide } \\ \text { GLP-1 } & \text { Glucagon-like peptide-1 } \\ \text { ORC } & \text { Orchidectomised mice } \\ \text { OVX } & \text { Ovariectomised mice } \\ \text { PAI-1 } & \text { Plasminogen activator inhibitor-1 } \\ \text { PCOS } & \text { Polycystic ovary syndrome } \\ \text { UCP1 } & \text { Uncoupling protein-1 } \\ \text { WAT } & \text { White adipose tissue }\end{array}$

\section{Introduction}

Glucocorticoids are widely used for their unsurpassed immunomodulatory effects. However, their use in humans is limited by significant adverse outcomes, including glucose intolerance, dyslipidaemia, hypertension, central obesity, loss of muscle mass and osteoporosis [1,2]. These side effects negatively affect adherence [3], and are also observed in endogenous glucocorticoid excess (Cushing's syndrome). Chronic glucocorticoid excess, irrespective of origin, is associated with increased morbidity and mortality $[1,4,5]$.

Glucocorticoid-induced central obesity, glucose intolerance, hypertension and dyslipidaemia are reminiscent of the metabolic syndrome, a phenotypic cluster that markedly increases the risk of coronary artery disease and type 2 diabetes [6]. Insulin resistance is the common underlying defect [7]. Glucocorticoids disrupt glucose homeostasis by stimulating the hepatic gluconeogenic enzymes PEPCK and glucose-6-phosphatase [8] and by interfering with insulin signalling in skeletal muscle [9]. In white adipose tissue (WAT), glucocorticoids increase lipolysis in subcutaneous depots, while enhancing adipogenesis 
and lipid accumulation in visceral fat [10]. Central obesity is a key component of the metabolic syndrome [6] and, like cardiovascular disease, is generally more pronounced in men than in premenopausal women [11]. In brown adipose tissue (BAT) of rodents and humans, chronic glucocorticoid treatment increases lipid accumulation, and may promote weight gain by suppressing thermogenesis $[12,13]$.

While investigating the metabolic response to chronic glucocorticoid exposure in mice, we found a striking sexual dimorphism. Male mice treated with corticosterone developed whole-body insulin resistance, hyperinsulinaemia, dyslipidaemia and obesity, but identically-treated female mice remained insulin-sensitive and lean. We therefore hypothesised that glucocorticoid-induced insulin resistance, dyslipidaemia and obesity were dependent on sex hormones. To test this hypothesis, orchidectomised and ovariectomised mice were treated with corticosterone under androgendeficient and androgen-replete conditions.

\section{Methods}

Housing, surgery and corticosterone treatment All experiments were performed in CD1 mice (obtained from Animal Resource Centre, Murdoch, WA, Australia). Mice were randomised to experimental groups using Microsoft Excel (Redmond, WA, USA). Baseline characteristics are shown in electronic supplementary material (ESM) Table 1 . Mice were maintained at $21^{\circ} \mathrm{C}$ on a $12: 12 \mathrm{~h}$ light-dark cycle, with ad libitum access to standard chow and water, with intake measured weekly. All experiments were conducted according to protocols approved by the institutional Animal Ethics Committee.

Surgery was performed under i.p. ketamine/xylazine anaesthesia $(80 \mathrm{mg} / \mathrm{kg}$ and $10 \mathrm{mg} / \mathrm{kg}$, respectively), 1 week before corticosterone treatment. For orchidectomy, testes were exteriorised via a scrotal incision, and the connecting vessels were tied with sutures. Testes were dissected out and the epididymis was kept intact. Orchidectomised mice are referred to, herein, as ORC. For ovariectomy, ovaries were dissected out through bilateral incisions on the lower anterior flank. Ovariectomised mice are referred to, herein, as OVX.

Androgen replacement was performed by subcutaneous implantation of a $0.25 \mathrm{~cm}$ Silastic implant (Dow Corning, Midland, MI, USA) containing dihydrotestosterone (DHT), in the lower back. In previous studies of gonadotropindeficient hypogonadal (hpg) mice, these implants produced a blood DHT concentration of $\sim 0.7 \mathrm{nmol} / 1$, which restored spermatocyte and spermatid numbers to levels observed in control mice [14].

From 8 weeks of age, mice were treated with corticosterone for 4 weeks. Corticosterone was dissolved in ethanol and added to the drinking water [15]. Based on water intake, all mice received $\sim 250 \mu \mathrm{g}$ corticosterone/day (see ESM Methods). Nocturnal serum corticosterone concentrations for all experimental groups are shown in ESM Fig. 1.

Body composition and insulin tolerance tests Lean and fat masses were measured by dual-energy $x$-ray absorptiometry (DXA) (Lunar PIXImus; GE Healthcare, Parramatta, NSW, Australia) at baseline and endpoint. Insulin tolerance tests (ITTs; $0.75 \mathrm{U}$ insulin $/ \mathrm{kg}$ ) were performed after 1 and 4 weeks of treatment [16]. Blood glucose concentrations were determined using an Accu-chek glucometer (Roche, North Ryde, NSW, Australia).

Biochemical measurements During the experiment, blood was collected by retro-orbital puncture. At the end of the experiment, mice were killed by cervical dislocation and blood was collected by cardiac puncture. After clotting, serum was collected by centrifugation at $10,000 \mathrm{~g}$ for $10 \mathrm{~min}$ at $4^{\circ} \mathrm{C}$, and stored at $-80^{\circ} \mathrm{C}$ until further analysis. Corticosterone concentrations were measured using an enzyme-linked immunosorbent assay (EIA; Arbor Assays, Ann Arbor, MI, USA), in serum collected between 22:00-24:00 hours. NEFA, triacylglycerol and cholesterol concentrations were measured in freshly-thawed samples of fasting serum, using colorimetric assays (WAKO Diagnostics, Mountain View, CA, USA). Glycerol concentrations were measured using a kit from Sigma-Aldrich (MAK117; St Louis, MO, USA). Fasting serum insulin, leptin, glucagon, ghrelin, glucagon-like peptide-1 (GLP-1), gastric inhibitory peptide (GIP), plasminogen activator inhibitor-1 (PAI-1) and resistin concentrations were measured in terminal samples using a Bio-Plex Pro Mouse Diabetes 8-Plex Assay (Bio-Rad, Hercules, CA, USA). Adiponectin concentrations were measured using a Bio-Rad Bio-Plex Pro Mouse Diabetes Adiponectin Assay (catalogue no. $171 \mathrm{~F} 7002 \mathrm{M})$. For all assays, the intra- and inter-assay CV was $<12 \%$.

Adipose tissue histology Adipose tissues were dissected out, weighed, fixed in $4 \%$ paraformaldehyde (wt/vol.) for $48 \mathrm{~h}$ at $4^{\circ} \mathrm{C}$, and paraffin-embedded. Tissues were cut into $5 \mu \mathrm{m} \mathrm{sec}-$ tions, mounted on glass slides and stained with H\&E. Adipocyte size was determined in three representative fields per section using ImageJ software (National Institutes of Health, Bethesda, MD, USA), by researchers blinded to experimental group.

Immunoblotting BAT samples were homogenised in ice-cold RIPA buffer $(65 \mathrm{mmol} / \mathrm{l}$ Tris $\mathrm{HCl}, 150 \mathrm{mmol} / \mathrm{l} \mathrm{NaCl}, 5 \mathrm{mmol} / \mathrm{l}$ EDTA, $1 \%$ NP-40 [vol./vol.], $0.5 \%$ sodium deoxycholate [wt/ vol.], $0.1 \%$ SDS [wt/vol.] and $10 \%$ glycerol [vol./vol.], $\mathrm{pH}$ 7.4) containing $1 \mathrm{mg} / \mathrm{l}$ aprotinin, $1 \mathrm{mg} / \mathrm{l}$ leupeptin, $10 \mathrm{mmol} / 1 \mathrm{NaF}, 1 \mathrm{mmol} / 1 \mathrm{Na}_{3} \mathrm{VO}_{4}$ and $1 \mathrm{mmol} / \mathrm{l}$ 
phenylmethylsulfonyl fluoride (PMSF). Equal amounts of cleared lysates from each group were pooled, and $10 \mu \mathrm{g}$ protein was electrophoresed in 4-12\% Bis-Tris NuPAGE gels (Life Technologies, Scoresby, VIC, Australia) and transferred to PVDF membranes. After blocking, membranes were incubated overnight in primary antibodies at $4^{\circ} \mathrm{C}$ with shaking. Primary antibodies for uncoupling protein-1 (UCP1) (catalogue no. ab10983; Abcam, Melbourne, VIC, Australia) and $\beta$-actin (catalogue no. 4967; Cell Signaling Technology, Danvers, MA, USA) were used at 1/1000 dilution (vol./vol.; diluted in TBS/T [ $20 \mathrm{mmol} / \mathrm{l}$ Tris $\mathrm{HCl}, 150 \mathrm{mmol} / \mathrm{l} \mathrm{NaCl}, 0.1 \%$ Tween-20 (vol./vol.)], pH 7.5). Primary antibodies were validated by detection of a band of the correct molecular weight in the target tissue (BAT). Anti-rabbit and anti-mouse secondary antibodies were obtained from Life Technologies (catalogue no. 656120) and GE Healthcare (NA931V), respectively, and were used at 1/10,000 dilution in TBS/T (vol./vol.). Densitometry was performed using ImageJ software.

RNA extraction and RT-PCR RNA was extracted using TRIzol Reagent (Thermo Fisher Scientific, Scoresby, VIC, Australia) and RNeasy mini kits (Qiagen, Germantown, MD, USA), and was reverse-transcribed using SuperScript III (Thermo Fisher Scientific). Gene expression levels were determined using quantitative real-time PCR, and were normalised to $18 \mathrm{~S}$ mRNA using the $\Delta \Delta \mathrm{C}_{\mathrm{t}}$ method. Primer sequences are provided in ESM Table 2.

Statistical analysis There were no criteria for exclusion of any data, samples or animals. Glycaemic responses to the ITT were calculated as inverse AUC, using a trapezoidal method in Microsoft Excel. The remaining analyses were performed using Prism 7 software (GraphPad Software, La Jolla, CA, USA). Group comparisons were performed using either Student's $t$ tests or a one-way ANOVA with Tukey's multiple comparison post hoc tests, as appropriate. Non-parametric tests were used for variables not normally distributed. In all cases, a two-sided $p<0.05$ was considered statistically significant.

\section{Results}

The metabolic response to chronic corticosterone treatment is sexually dimorphic in mice Male and female mice exhibited a marked sexual dimorphism in their metabolic responses to chronic corticosterone $(\sim 250 \mu \mathrm{g} /$ day) treatment (Fig. 1). Insulin resistance was established in male, but not female, mice within 7 days (ESM Fig. 2). After 4 weeks, males but not females had developed severe insulin resistance (Fig. 1ac) and fasting hyperinsulinaemia (Fig. 1d).

Four weeks of corticosterone treatment also increased adiposity in male, but not female mice (Fig. 1e); and corticosterone treatment prevented both males and females from gaining lean mass (Fig. 1f). Corticosterone treatment did not significantly influence food intake in intact mice (ESM Fig. 3), or affect fasting NEFA concentrations (Fig. 1g). Notably, male mice treated with corticosterone developed marked dyslipidaemia (higher fasting triacylglycerol and cholesterol), while females did not (Fig. 1h, i).

Ovariectomy does not affect insulin sensitivity but exacerbates corticosterone-induced fat accrual and hypercholesterolaemia These findings led us to hypothesise that the sexually dimorphic effects of chronic corticosterone treatment on metabolism were sex hormone-dependent. Next, we treated OVX female mice with either vehicle or corticosterone for 4 weeks, as above (Fig. 2). Ovariectomy alone did not affect insulin sensitivity or insulinaemia, and there was no additional effect of corticosterone treatment on these variables (Fig. 2a-c). However, compared with intact females, corticosteronetreated OVX mice gained a significant amount of fat mass (Fig. 2d), despite eating less (ESM Fig. 3).

Ovariectomy also partially prevented gains in lean mass, although this was further reduced by corticosterone treatment (Fig. 2e). OVX mice had similar fasting serum NEFA and triacylglycerol concentrations compared with intact female mice, and these variables were not altered by corticosterone treatment (Fig. 2f, g). Corticosterone treatment significantly increased fasting cholesterol in OVX mice, however (Fig. 2h). Therefore, although female sex hormones protected mice from fat accumulation and hypercholesterolaemia in response to corticosterone treatment, ovariectomy did not affect basal or corticosterone-induced insulin resistance.

Androgens are required for corticosterone-induced insulin resistance and hyperinsulinaemia, and exacerbate fat accrual and dyslipidaemia We also examined the effects of androgen deficiency on these phenotypes, by chronically administering corticosterone to ORC male mice. Orchidectomy alone significantly reduced food intake (ESM Fig. 3) and led to a $32 \%$ improvement in the insulin response $(p<0.05)$ compared with intact male mice (Fig. 3a, b). Although this improvement was negated by corticosterone treatment, ORC mice treated with corticosterone were not insulin resistant per se, as their insulin responses and insulinaemia were indistinguishable from intact male mice (see Fig. 1 vs Fig. 3c). Moreover, this pattern was established as early as 7 days from commencing corticosterone treatment (ESM Fig. 2). This observation suggested that androgens were required for corticosterone-induced insulin resistance and hyperinsulinaemia.

Regarding fat accumulation, orchidectomy alone did not increase fat mass compared with intact male mice (Fig. 3d), and corticosterone-treated ORC mice accumulated similar amounts of fat to intact corticosterone-treated males. As would be expected in androgen deficiency, ORC males gained less lean mass than intact male mice, and this was further 
Fig. 1 The metabolic response to 4 weeks of chronic corticosterone treatment is sexually dimorphic in mice. (a) ITT in male mice. Filled circles, Veh $(n=14)$; unfilled circles, CS $(n=18)$. (b) ITT in female mice. Filled squares, Veh $(n=24)$; unfilled squares, CS $(n=22)$. (c) Inverse AUC for ITT. (d) Fasting serum insulin concentrations. $n=10,12,7$ and 9 for male Veh, male CS, female Veh and female CS, respectively. (e) Fat mass change. $n=14,18$, 24 and 22 for male Veh, male CS, female Veh and female CS, respectively. (f) Lean mass change. Sample sizes as in (e). (g) Fasting serum NEFA concentrations. $n=9,8,8$ and 9 for male Veh, male CS, female Veh and female CS, respectively. (h) Fasting serum triacylglycerol concentrations. $n=10,13,9$ and 8 for male Veh, male CS, female Veh and female CS, respectively. (i) Fasting plasma cholesterol concentrations. Sample sizes as in (h). Results are shown as mean \pm SEM. $* * p<0.01, * * * p<0.001$
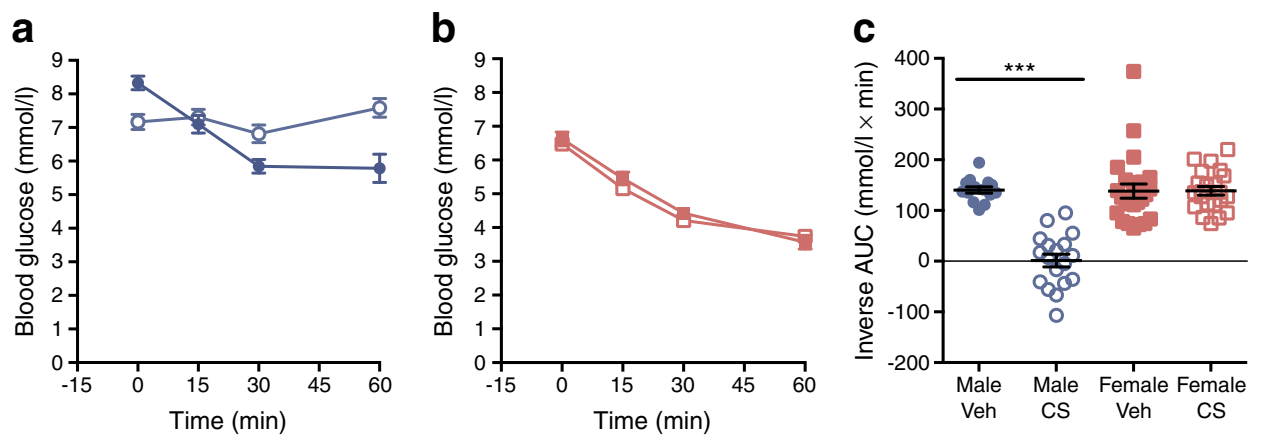

d
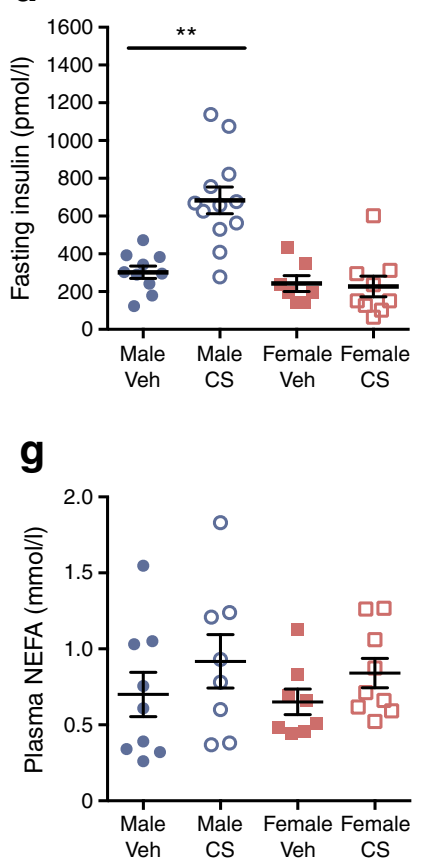

e
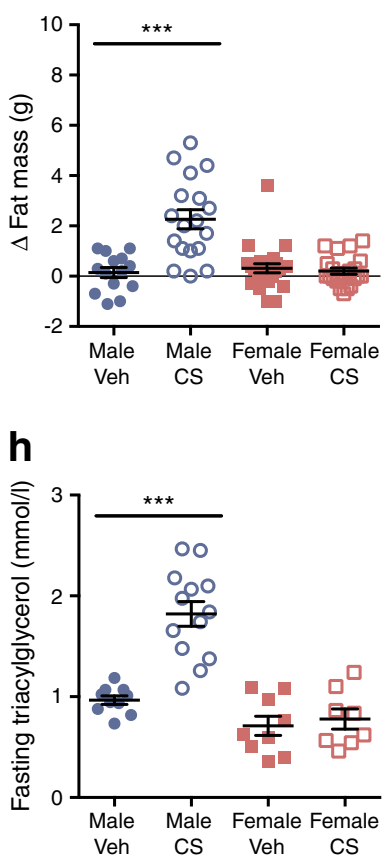

f

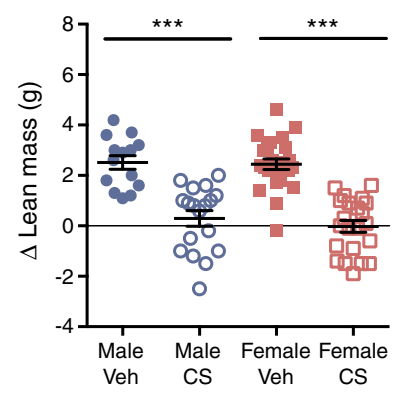

i

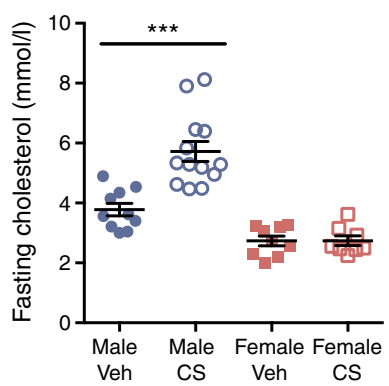

exacerbated in corticosterone-treated ORC mice, into a net loss of lean mass (Fig. 3e). Orchidectomy alone did not significantly affect fasting serum NEFA, triacylglycerol or cholesterol concentrations (Fig. 3f-h). Corticosterone treatment increased fasting triacylglycerol and cholesterol concentrations in ORC mice, although only the cholesterol concentrations were increased above levels observed in intact, male mice. Therefore, orchidectomy prevented corticosteroneinduced insulin resistance, hyperinsulinaemia and, to some extent, hypertriacylglycerolaemia, but did not prevent hypercholesterolaemia or deleterious changes in body composition in response to corticosterone. These results suggested that the insulin resistance-related response to chronic corticosterone treatment required androgens.

Next, we investigated glucocorticoid-induced insulin resistance in female mice implanted with DHT. While DHT alone did not influence insulin responses in female mice, corticosterone treatment produced marked insulin resistance (Fig. 4).

Finally, to confirm the effects of androgens on corticosterone-induced insulin resistance, and to remove the possible protective effects of ovarian hormones, gonadectomised mice (ORC males and OVX females) were implanted with DHT and treated with either vehicle or corticosterone, as above (Fig. 5). DHT treatment alone did not alter insulin sensitivity or fat accumulation in either ORC males or OVX females (Fig. 5a-e vs Fig. 1a-e), and food intake was restored to levels observed in intact male and female mice (ESM Fig. 3). DHT treatment restored the gain of lean mass in ORC males to that observed in intact males, and augmented the gain of lean mass in OVX females by $\sim 30 \%$ (Fig. $5 f$ ), compared with intact females (Fig. 1f).

In this model, DHT exacerbated corticosterone-induced insulin resistance and fat mass accumulation in both sexes. In ORC males treated with DHT, corticosterone not only produced marked insulin resistance (Fig. 5a, c) and hyperinsulinaemia (Fig. 5d), but also produced an even greater degree of fat mass accumulation compared with intact corticosterone-treated males (Fig. 1e). Similarly, OVX females were susceptible to corticosterone-induced insulin resistance and obesity when treated with DHT (Fig. 5c, e). 
Fig. 2 In female mice, ovariectomy did not affect insulin sensitivity, but exacerbated fat accumulation and

cholesterolaemia associated with 4 weeks of corticosterone treatment. In (b-h) the dotted line shows the mean result for intact female mice treated with vehicle ('female Veh' data from Fig. 1). (a) ITT in OVX females. Filled triangles, OVX treated with vehicle (OVX Veh; $n=15$ ); unfilled triangles, OVX treated with corticosterone (OVX CS; $n=16$ ). (b) Inverse AUC for ITT. (c) Fasting serum insulin concentrations. OVX Veh, $n=8$; OVX CS, $n=10$. (d) Fat mass change. OVX Veh, $n=15$; OVX $\mathrm{CS}, n=16$. (e) Lean mass change. OVX Veh, $n=15$; OVX CS, $n=16$. (f) Fasting serum NEFA concentrations. OVX Veh, $n=12$; OVX CS, $n=10$. (g) Fasting serum triacylglycerol concentrations. $n=10$ per group. (h) Fasting serum cholesterol concentrations. $n=10$ per group. Results are shown as mean \pm SEM. There were no significant differences between OVX Veh and OVX CS mice for any of the variables measured. $* p<0.05$, $* * * p<0.001$ vs female Veh
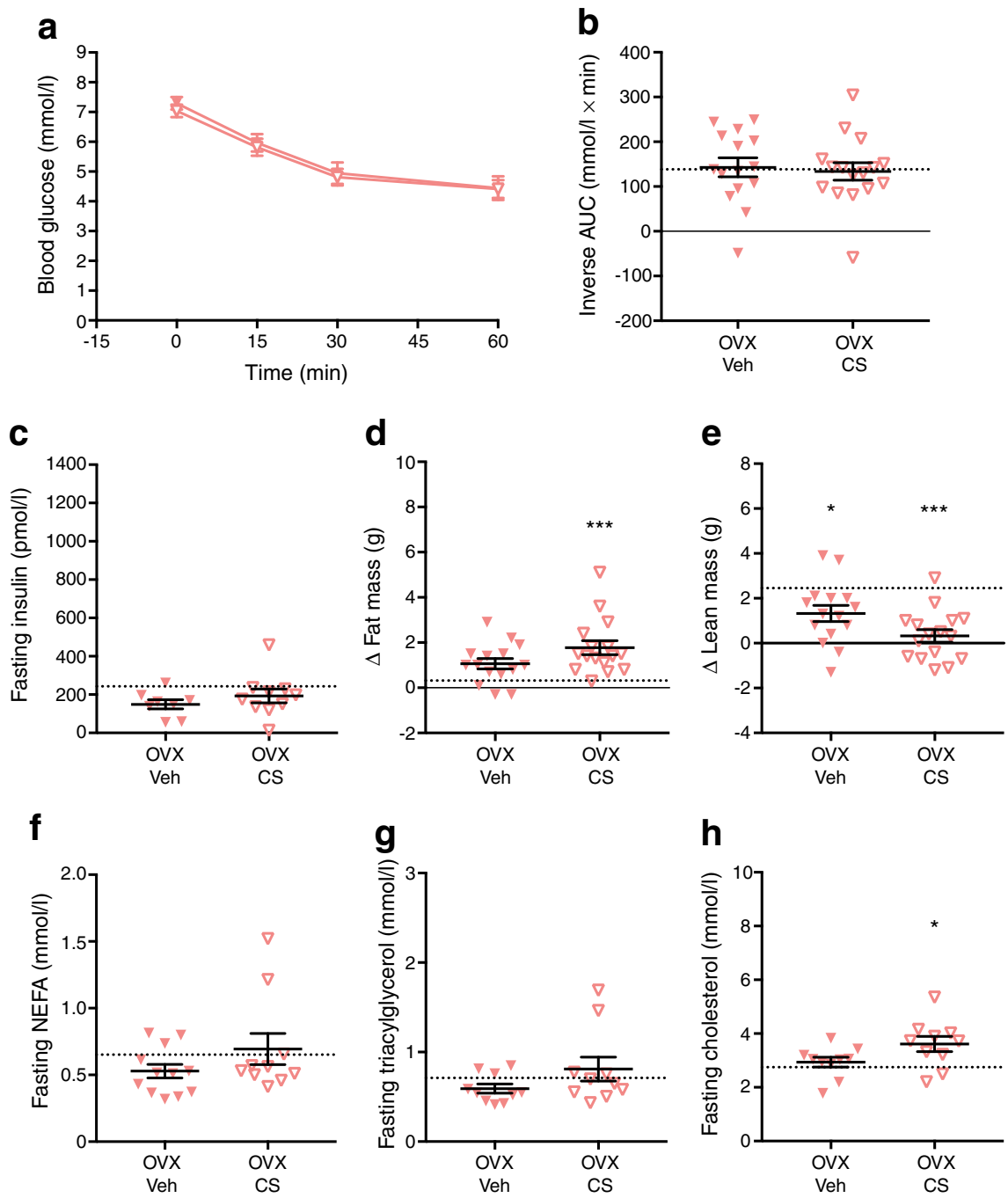

In contrast, corticosterone-induced musculoskeletal changes did not require androgens. Despite an increased gain of lean mass in DHT-treated ORC and OVX mice, this did not prevent loss of lean mass in response to corticosterone (Fig. 5f). In DHT-treated ORC and OVX mice, no significant changes in fasting NEFA were observed (Fig. 5g), although corticosterone treatment increased fasting serum triacylglycerol and cholesterol in both sexes (Fig. 5h, i).

\section{Androgens potentiate glucocorticoid actions in BAT and WAT}

To better understand the requirement of androgens for glucocorticoid-induced insulin resistance, as well as the effects of DHT on fat accumulation, we examined BAT and WAT from the above groups of mice.

In BAT, glucocorticoids suppress thermogenesis and increase lipid accumulation $[12,13]$. In androgen-replete, but not in androgen-deficient mice, corticosterone treatment produced a significant increase in both the interscapular BAT mass and the size of lipid droplets within it (Fig. 6a-f). Consistent with this 'whitening' of BAT, in intact males, corticosterone treatment reduced UCP1 protein by $\sim 8 \%$ (Fig. $6 \mathrm{~g}$ ). Orchidectomy increased basal UCP1 protein content by nearly $60 \%$ above baseline; and in DHT-treated ORC males, corticosterone treatment suppressed UCP1 levels by $\sim 30 \%$. In BAT, there were no significant changes in mRNAs encoding Ppargcla, Pparg, Acaca or Fasn, suggesting that changes in lipid accumulation according to androgen status and/or corticosterone treatment did not directly involve mitochondrial biogenesis, adipogenesis or lipogenesis (Fig. 6h-k).

In WAT, glucocorticoids approximately doubled gonadal and inguinal fat pad masses in both intact and ORC males (Fig. 7a and Fig. 7e, respectively), consistent with the observed changes in overall adiposity. Adipocyte hypertrophy was minor in both depots, suggesting that increased adipogenesis also contributed to increased fat mass (Fig. 7c, g). Fasting serum glycerol concentrations, a measure of basal WAT lipolysis, were 
Fig. 3 In male mice, orchidectomy prevents insulin resistance and hyperinsulinaemia, but not fat accumulation or dyslipidaemia, following 4 weeks of corticosterone treatment. In (be) the dotted line shows the mean result for intact males treated with vehicle ('male Veh' data from Fig. 1). (a) ITT in ORC males. Filled triangles, ORC treated with vehicle (ORC Veh; $n=16$ ); unfilled triangles, ORC treated with corticosterone (ORC CS; $n=9$ ). (b) Inverse AUC for ITT. ORC Veh, $n=16$; ORC CS, $n=9$. (c) Fasting serum insulin concentrations. $n=9$ per group. (d) Fat mass change. ORC Veh, $n=16$; ORC CS, $n=12$. (e) Lean mass change. ORC Veh, $n=16$; ORC CS, $n=12$. (f) Fasting serum NEFA concentrations. $n=10$ per group. (g) Fasting serum triacylglycerol concentrations. ORC Veh, $n=11$; ORC CS, $n=12$. (h) Fasting serum cholesterol concentrations. ORC Veh, $n=11$; ORC CS, $n=12$. Results are shown as mean \pm SEM. $* p<0.05$, $* * * p<0.001$ vs male Veh; ${ }^{\dagger} p<0.05,{ }^{\dagger} p<0.01,{ }^{\dagger \dagger} p<0.001$ vs ORC Veh a

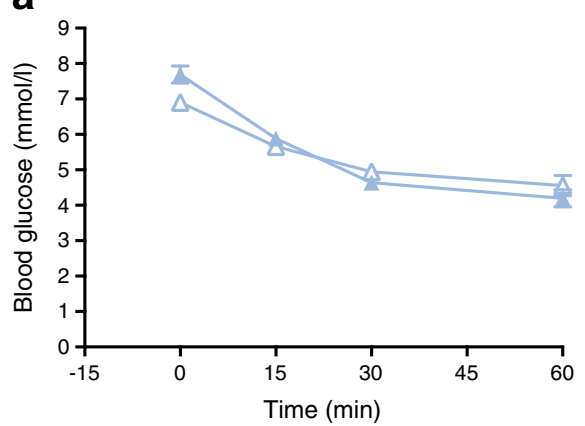

C

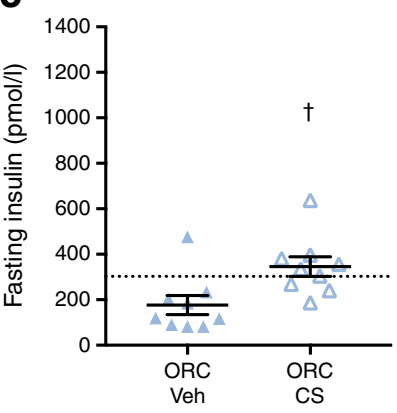

d

f

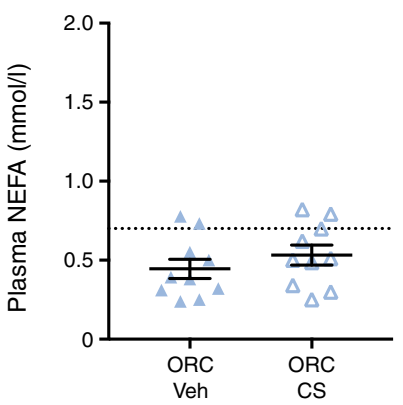

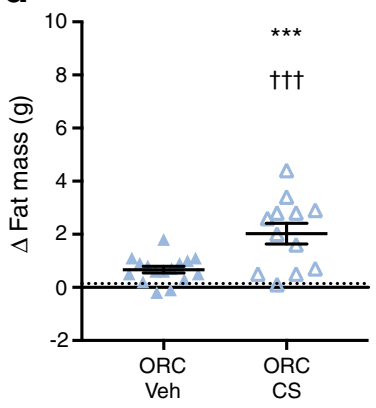

b

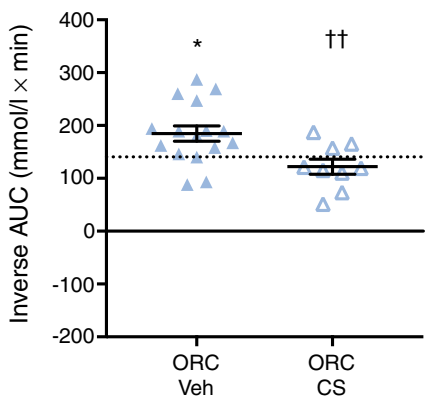

e

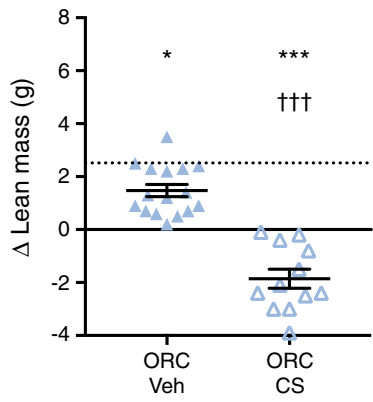

h

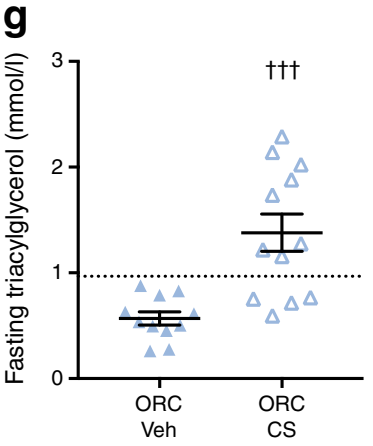

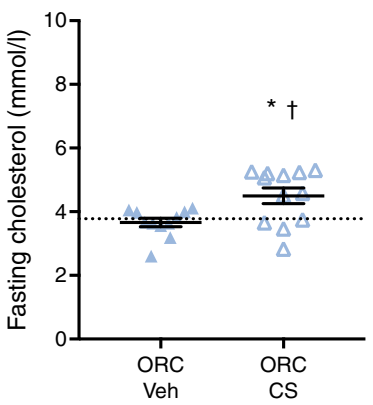

not significantly different between groups (ESM Fig. 4). Notably, DHT exerted potent effects on corticosteroneinduced fat accumulation and adipocyte hypertrophy in males, particularly in inguinal fat. In female mice, similarly, DHT and corticosterone treatment caused marked accumulation of gonadal and inguinal fat (Fig. 7b, f), and these changes were attributable to adipocyte hypertrophy, especially in gonadal fat (Fig. 7d, h).

Given that DHT is a more potent agonist of the androgen receptor than testosterone [17], we next explored the possibility that androgens potentiate glucocorticoid action in WAT. First, we measured the mRNA expression of Gilz, a glucocorticoid target gene that encodes the glucocorticoid-induced leucine zipper protein [18], in gonadal WAT. In intact males, corticosterone treatment induced Gilz mRNA expression in WAT by 3.7 -fold ( $p<0.01$, Fig. 8a). Similarly, Gilz expression was induced by corticosterone in WAT from OVX female mice treated with DHT (by 5.6-fold, $p<0.01$ ); but not in WAT from male ORC or DHT-treated ORC mice.
Next, we measured mRNA expression of the androgen receptor $(A r)$ in gonadal WAT: $A r$ mRNA was increased (by 2.4 -fold, $p<0.05$ ) by corticosterone in ORC males; and was suppressed by corticosterone in ORC males treated with DHT (by 53\%, $p<0.05$, Fig. 8b). Similarly, glucocorticoid receptor $(\mathrm{Nr} 3 \mathrm{cl})$ mRNA expression was decreased by corticosterone in DHT-treated ORC males (by $35 \%, p<0.05$, Fig. 8c), and was highest in OVX females treated with DHT and corticosterone $(66 \%$ increase over male vehicle-treated mice, $p<0.05)$. Androgen status and corticosterone treatment did not affect Pparg mRNA expression in WAT (Fig. 8d).

Effects of androgens and corticosterone on obesity- and diabetes-related hormones Testosterone suppresses circulating adiponectin concentrations [19]. To characterise the requirement for androgens in corticosterone-induced insulin resistance, we measured a panel of obesity- and diabetes-related hormones in these mice (ESM Table 3). 
a

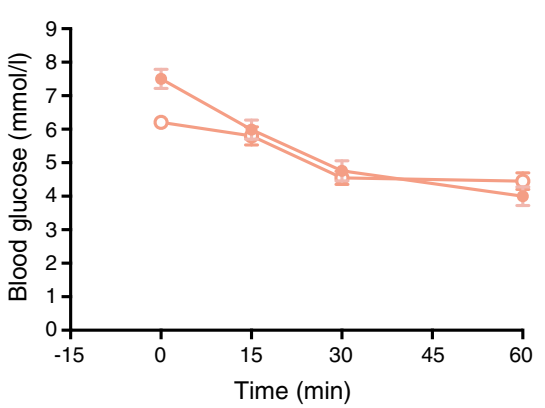

C

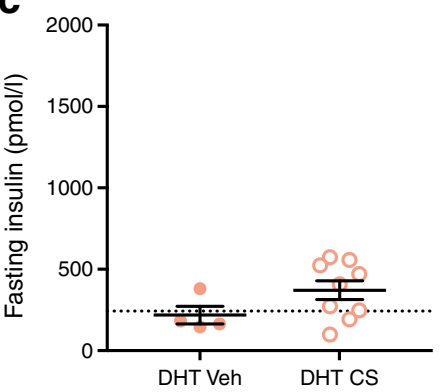

d

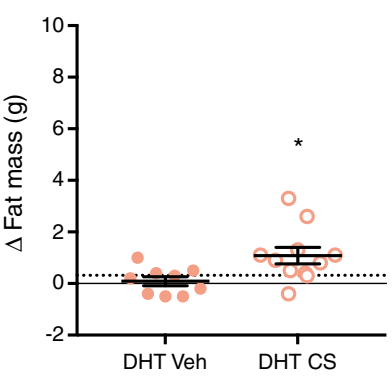

b

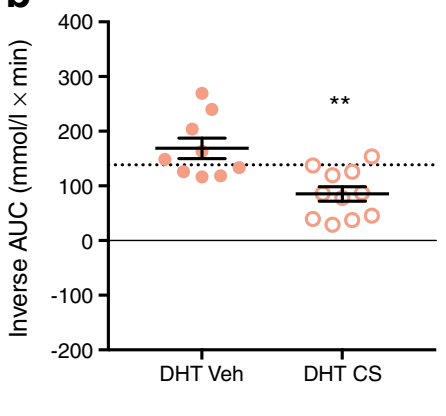

Fig. 4 In intact female mice treated with DHT, 4 weeks of corticosterone treatment leads to insulin resistance, fat accumulation and a failure to gain lean mass. In (b-e) the dotted line shows the mean result for intact females treated with vehicle ('female Veh' data from Fig. 1). (a) ITT in intact female mice treated with DHT. Filled circles, DHT and vehicle-treated (DHT Veh; $n=9$ ); unfilled circles, DHT and corticosterone-treated (DHT

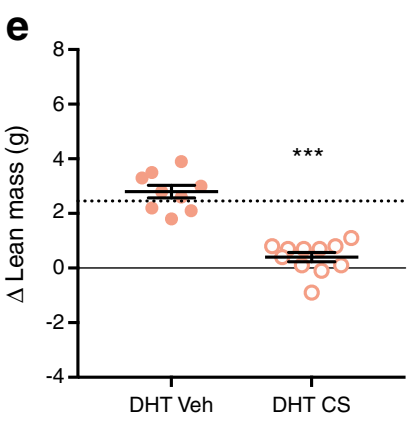

CS; $n=11$ ). (b) Inverse AUC for ITT. DHT Veh, $n=9$; DHT CS, $n=11$. (c) Fasting serum insulin. DHT Veh, $n=4$; DHT CS, $n=9$. (d) Fat mass change. DHT Veh, $n=9$; DHT CS, $n=11$. (e) Lean mass change. DHT Veh, $n=9$; DHT CS, $n=11$. Results are shown as mean \pm SEM. $* p<0.05, * * p<0.01$, *** $p<0.001$ vs DHT Veh
Although androgens (in intact male mice and in DHT-treated males and females) alone were associated with lower serum adiponectin concentrations, corticosterone-induced insulin resistance in this model did not involve additional suppression of adiponectin. Second, corticosterone treatment increased serum leptin concentrations, but only when androgens were present. Without androgens, and even when corticosterone treatment increased adiposity (male ORC mice, female OVX mice), there was no corresponding increase in serum leptin concentrations (ESM Table 3 and ESM Fig. 5). Fasting serum concentrations of resistin, PAI-1, GLP-1 and GIP did not change significantly in males or females as a result of orchidectomy, ovariectomy or treatment with corticosterone/DHT (data not shown).

\section{Discussion}

Glucocorticoid excess causes central adiposity, dyslipidaemia and insulin resistance, phenotypes that closely parallel the metabolic (insulin resistance) syndrome. Here, using gonadectomy and androgen treatment (DHT) in mice of both sexes, we found that corticosterone-induced insulin resistance, hyperinsulinaemia and, to some extent, dyslipidaemia were androgen-dependent, while changes in lean mass following corticosterone treatment were not. Finally, although androgens were not required for corticosterone-induced WAT accumulation, they stimulated intracellular lipid accumulation ('whitening') in BAT, and DHT augmented corticosteroneinduced fat accumulation in mice of both sexes.

Androgen- and glucocorticoid-induced insulin resistance in this model had several key features. Although glucocorticoids stimulate hepatic gluconeogenesis [8], here, chronic corticosterone treatment suppressed fasting blood glucose, in combination with marked insulin resistance, but only when androgens were present (Figs 1, 2, 3, 4 and 5). This may either reflect intact hepatic responses to corticosterone- and androgen-induced hyperinsulinaemia, or possibly direct suppression of PEPCK by testosterone [20].

In the liver, sexually dimorphic effects of glucocorticoids on gene expression, related to cell death, differentiation and inflammation, have been reported in rats, following a single dose of dexamethasone [21]. Sex-specific effects on gluconeogenic genes were not examined in [21], although the hepatocyte nuclear factor 4 a (Hnf4a) signalling pathway was differentially induced. Interestingly, an androgen antagonist, enzalutamide, attenuates hepatic glucocorticoid signalling in male mice treated with corticosterone [22]. Further studies will be required to investigate how androgens influence glucocorticoid actions in the liver. 

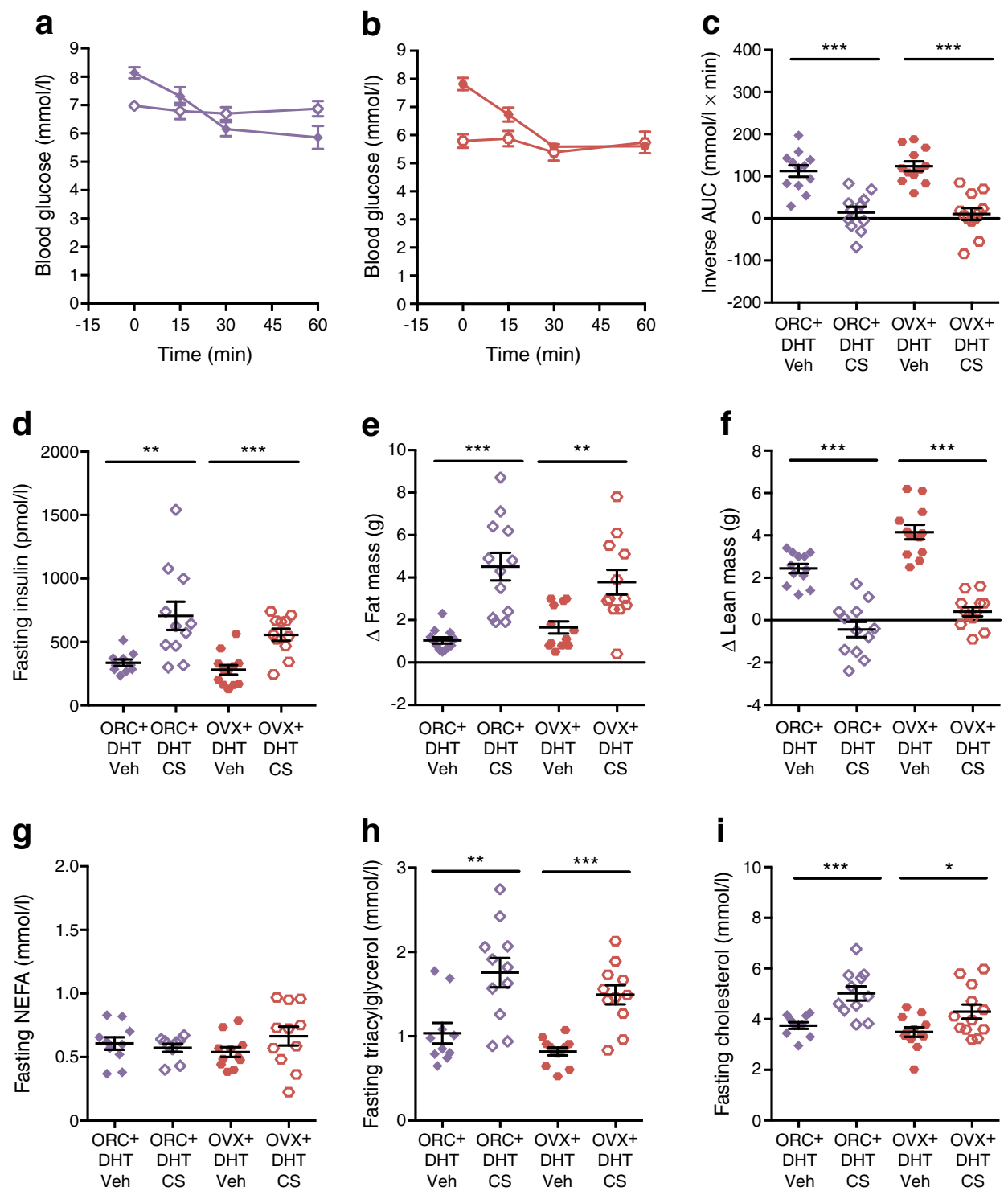

Fig. 5 In ORC and OVX mice treated with DHT, 4 weeks of corticosterone treatment leads to insulin resistance, hyperinsulinaemia, fat accumulation, loss of lean mass and dyslipidaemia. (a) ITT in ORC males treated with DHT. Filled diamonds, ORC males treated with DHT and vehicle (ORC+DHT Veh; $n=12)$; unfilled diamonds, ORC mice treated with DHT and corticosterone (ORC+DHT CS; $n=11$ ). (b) ITT in OVX females treated with DHT. Filled hexagons, OVX+DHT Veh $(n=12)$; unfilled hexagons, OVX+DHT CS, $(n=12)$. (c) Inverse AUC for ITT. ORC+DHT Veh, $n=12$; ORC+DHT CS, $n=11$; . OVX+DHT Veh, $n=12$; OVX+DHT CS, $n=12$. (d) Fasting serum insulin. $n=10,11$,

Due to the marked effects of glucocorticoids on adiposity, we focused instead on adipose tissue, where androgens potentiated many glucocorticoid effects. First, in BAT, chronic corticosterone treatment promoted lipid accumulation ('whitening') (Fig. 6), but only when androgens were present. BAT whitening has been reported previously in male rats and mice treated with corticosterone $[12,23]$, and it requires glucocorticoid receptors in adipose tissue [24]. We did not observe any changes in
12 and 11 for ORC+DHT Veh, ORC+DHT CS, OVX+DHT Veh and OVX+DHT CS, respectively. (e) Fat mass change. $n=12$ per group. (f) Lean mass change. $n=12$ per group. (g) Fasting serum NEFA concentrations. $n=10,9,11$ and 11 for ORC+DHT Veh, ORC+DHT CS, OVX+ DHT Veh and OVX+DHT CS, respectively. (h) Fasting serum triacylglycerol. $n=10,11,12$ and 11 for ORC+DHT Veh, ORC+DHT CS, $\mathrm{OVX}+\mathrm{DHT}$ Veh and OVX+DHT CS, respectively. (i) Fasting serum cholesterol. $n=10,11,12$ and 12 for ORC+DHT Veh, ORC+DHT CS, OVX+DHT Veh and OVX+DHT CS, respectively. Results are shown as mean \pm SEM. $* p<0.05, * * p<0.01, * * * p<0.001$

adipogenic (Pparg) or lipogenic (Acaca, Fasn) mRNA expression. BAT lipogenesis is generally low in mice that are not cold-acclimatised [25].

Notably, as in male mice lacking either the scaffold protein p62 [26] or Vegfa in adipose tissue [27], whitening of BAT coincided with insulin resistance. Mitochondrial dysfunction $[26,27]$ and inflammation [28] may link BAT whitening with whole-body insulin resistance, obesity and glucose intolerance. 

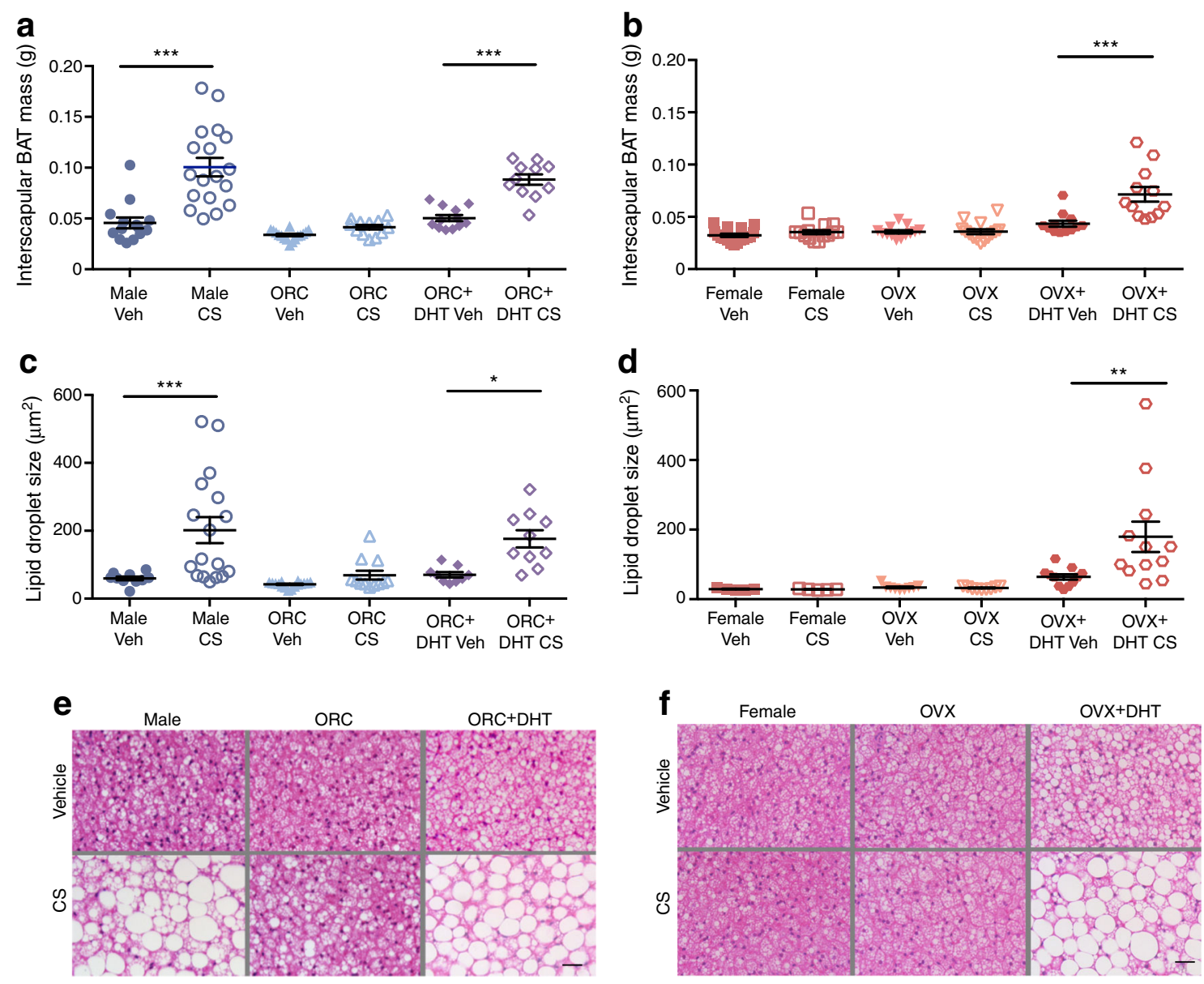

g
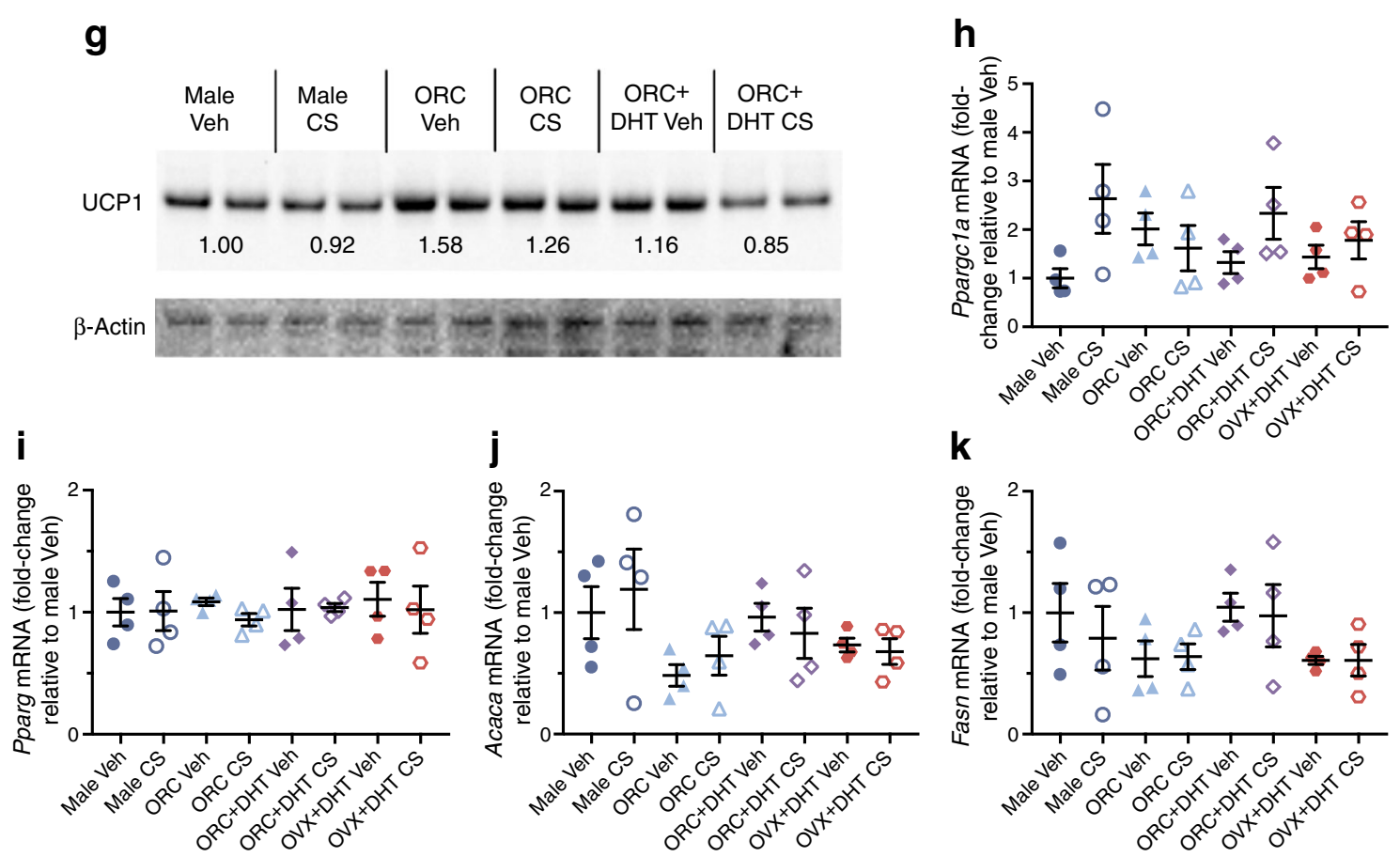

Here, treatment of gonadectomised mice with DHT, a more potent and non-aromatisable agonist of the androgen receptor than testosterone [17], augmented the inhibitory effects of corticosterone on UCP1 protein expression in BAT 
4 Fig. 6 Androgens are required for corticosterone-induced expansion and whitening of BAT. (a) Interscapular BAT mass in males. $n=14,18,16$, 12,12 and 11 for males treated with vehicle (Veh), males treated with corticosterone (CS), ORC Veh, ORC CS, ORC+DHT Veh and ORC+ DHT CS, respectively. (b) Interscapular BAT mass in females. $n=17$, 14, 13, 14, 12 and 12 for female Veh, female CS, OVX Veh, OVX CS, OVX+DHT Veh and OVX+DHT CS mice, respectively. (c) Mean lipid droplet size in male interscapular BAT. $n=10,17,16,12,9$ and 10 for male Veh, male CS, ORC Veh, ORC CS, ORC+DHT Veh and ORC+ DHT CS, respectively. (d) Mean lipid droplet size in female interscapular BAT. $n=5,5,9,9,11$ and 12 for female Veh, female CS, OVX Veh, OVX CS, OVX+DHT Veh and OVX+DHT CS mice, respectively. (e-f) Representative histological appearance of interscapular BAT in the male (e) and female (f) mouse models studied. Scale bars, $50 \mu \mathrm{m}$. (g) Protein expression of UCP1 in interscapular BAT from male mice. Equal amounts of BAT lysates from six individual mice were pooled, and $10 \mu \mathrm{g}$ of lysate was electrophoresed in duplicate lanes, as described in the ESM Methods. $\beta$-Actin is shown as a loading control, and relative expression (compared with male Veh) is shown for each pair of lanes. (hk) BAT mRNA expression of Ppargcla (h), Pparg (i), Acaca (j) and Fasn (k). All genes were normalised to $18 \mathrm{~S}$ mRNA and shown as foldchange, relative to male Veh group. In (h-k), $n=4$ per group; $p>0.05$, Kruskal-Wallis test. Results are shown as mean \pm SEM. ${ }^{*} p<0.05$, $* * p<0.01, * * * p<0.001$

(Fig. 6g). Inhibitory effects of androgens on BAT function are supported by studies in rats [29] and in isolated brown adipocytes [30]. Women generally have a higher incidence of metabolically-active BAT than men [31], and when fed a high-fat diet, female rats gain less weight than males, and their BAT expresses higher levels of proteins related to thermogenesis and lipid oxidation [32]. Interestingly, a recent study of androgen- and glucocorticoid-treated male mice did not report any significant effects on Ucpl mRNA expression in BAT [22], although UCP1 protein was not measured.

Our second major finding was that DHT produced marked WAT accumulation and adipocyte hypertrophy (in both gonadal [central] and inguinal [subcutaneous] fat), when corticosterone was also administered. Synergistic effects of DHT and corticosterone on adiposity were not observed in a recent study of male mice [22], but this may reflect the shorter study duration.

Third, we found that androgens were required for glucocorticoid signalling (Gilz mRNA) in WAT from intact males, ORC males, and OVX females treated with DHT (Fig. 7). Together with the whole-body insulin responses, this led us to conclude that androgens sensitise mice to glucocorticoidinduced insulin resistance and fat accumulation. This idea is well supported by a recent study of male mice, which examined Gilz expression, as well as that of the glucocorticoid target genes FK506 binding protein 5 (Fkbp5) and metallothionein 2A (Mt2a) [22].

The androgen receptor and glucocorticoid receptor are members of the same nuclear receptor superfamily [33] and show affinity for common DNA hormone receptor elements [34]. In prostate cancer cells, for example, the androgen receptor and glucocorticoid receptor share many target genes, and glucocorticoid receptor enables some cells to evade pharmacological blockade of the androgen receptor by increasing androgen receptor expression and compensating for this receptor at common target genes [35]. Our results for $A r$ and Nr3cl mRNA expression in WAT (Fig. 8) support the idea that these nuclear receptors regulate their own activity, as well as that of the other, by controlling receptor expression.

In DHT-treated ORC males, corticosterone did not induce Gilz expression in WAT, however (Fig. 8). This was likely due to downregulation of both $\mathrm{Ar}$ and $\mathrm{Nr} 3 \mathrm{cl}$ mRNA expression by corticosterone in DHT-treated males. High androgen levels suppress $A r$ expression in other cell types [36]. Interestingly, in the absence of androgens, Ar mRNA expression was increased by corticosterone treatment (Fig. 8b), further supporting androgen receptor-glucocorticoid receptor crosstalk. Future studies should examine whether expression of other glucocorticoid-responsive genes (such as Dusp1, Insig 2, Lcn 2, Pik3rl and Ptgs, implicated in adipocyte insulin action [37]) are also androgen-regulated.

Finally, while androgens suppress secretion of the insulinsensitising hormone adiponectin from adipocytes [19], corticosterone-induced insulin resistance did not involve additional suppression of adiponectin.

This study is the first to identify a clear sexual dimorphism in the metabolic response to chronic glucocorticoid exposure in mice. The experimental design, involving gonadectomy and androgen replacement in both sexes, was a major strength of the study, and it also revealed protective actions of female sex hormones (see below). Our results are unlikely to be strain-dependent, as concordant results have been recently obtained in separate studies of male [22] and female [38] C57BL/6 mice.

There were some limitations, however. First, energy expenditure was not assessed, although food intake was measured throughout the study. Relative to intact mice, food intake was significantly reduced by orchidectomy and ovariectomy (ESM Fig. 3), although this did not explain the development of insulin resistance. OVX females treated with DHT and corticosterone ate the same amount as intact, corticosteronetreated females, yet only the former group were insulin resistant. Moreover, in corticosterone-treated mice, insulin resistance was established within 7 days (ESM Fig. 2 and [16]), prior to effects on food intake. In androgen-replete mice, corticosterone treatment did not affect food intake; therefore, we can infer that any changes in adiposity were due to suppression of energy expenditure.

Also, whole-body measures of insulin responsiveness were used here, rather than the gold standard measure, the hyperinsulinaemic-euglycaemic clamp. Hyperinsulinaemia was a confounding variable for weight gain [39], and we were unable to determine whether this was due to increased basal insulin secretion, or reduced hepatic insulin clearance [40]. 

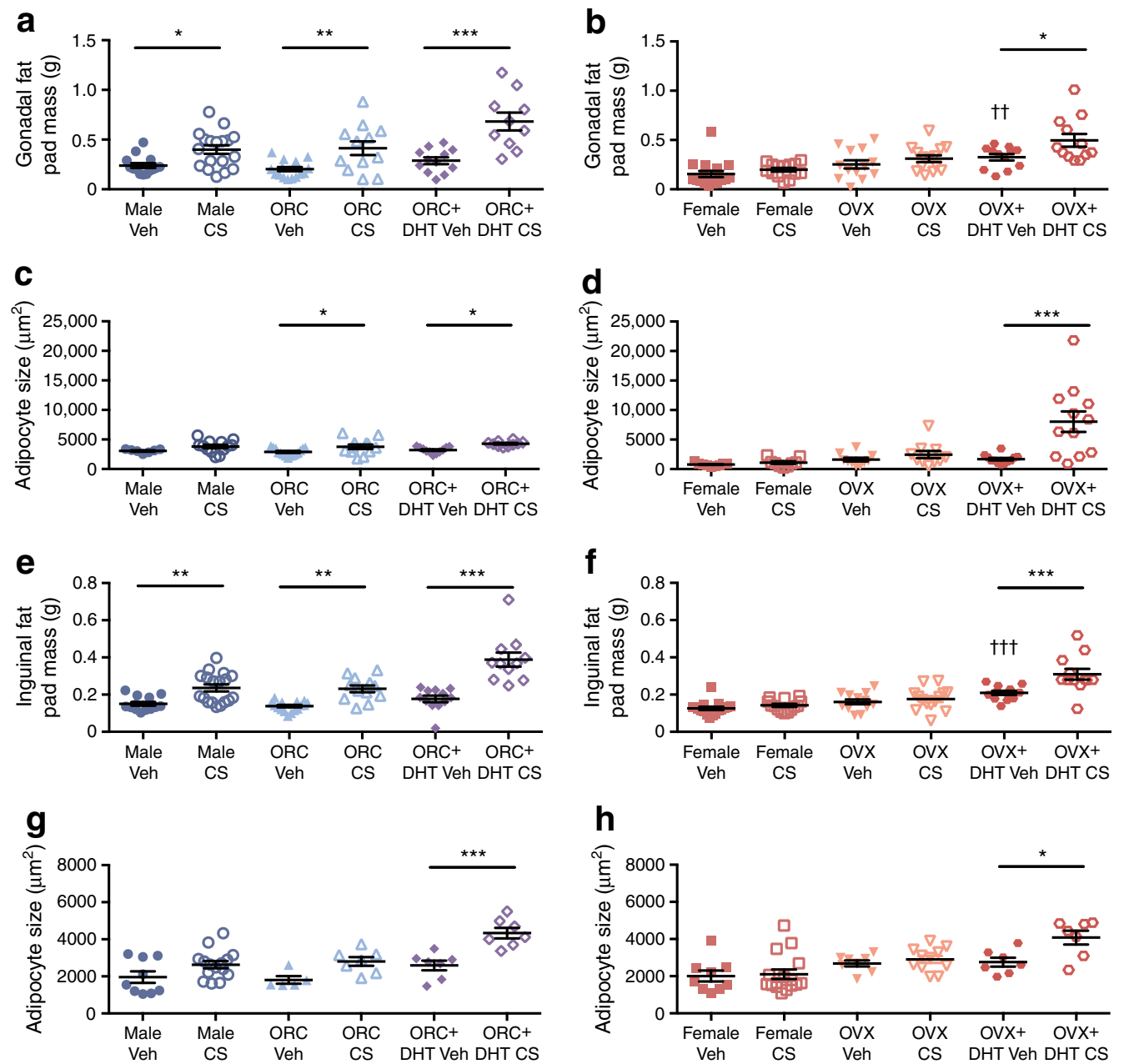

Fig. 7 Fat pad mass and adipocyte size in gonadal and inguinal fat from intact, ORC, OVX and DHT-treated mice following 4 weeks of corticosterone treatment. (a) Gonadal fat pad mass in males. $n=14,18,16,12$, 12 and 10 for males treated with vehicle (Veh), males treated with corticosterone (CS), ORC Veh, ORC CS, ORC+DHT Veh and ORC+DHT CS, respectively. (b) Gonadal fat pad mass in females. $n=17,14,13,14$, 12 and 12 for female Veh, female CS, OVX Veh, OVX CS, OVX+DHT Veh and OVX+DHT CS mice, respectively. (c) Mean adipocyte size in gonadal fat in males. $n=7,13,15,12,11$ and 10 for male Veh, male CS, ORC Veh, ORC CS, ORC+DHT Veh and ORC+DHT CS, respectively. (d) Mean adipocyte size in gonadal fat in females. $n=5,5,9,9,11$ and 12

Regardless, our results at both the whole-animal and tissue levels support our conclusion that androgens sensitise mice to glucocorticoids, promoting insulin resistance and fat accumulation. Co-operation between androgen receptor and glucocorticoid receptor signalling may partially explain why adipogenesis is impaired in glucocorticoid receptor-deficient pre-adipocytes in vitro, but their implantation into male mice yields fullyformed fat pads [41]. Androgens may augment glucocorticoid receptor function by inducing expression of its sensitisers; for example Bagl and Ppid are differentially induced by chronic stress in the hippocampus of male and female mice [42].

for female Veh, female CS, OVX Veh, OVX CS, OVX+DHT Veh and OVX+DHT CS mice, respectively. (e) Inguinal fat pad mass in males. Sample sizes as in (a). (f) Inguinal fat pad mass in females. Sample sizes as in (b). (g) Mean adipocyte size in inguinal fat in males. $n=8,15,5,7,7$ and 7 for male Veh, male CS, ORC Veh, ORC CS, ORC+DHT Veh, and ORC+DHT CS, respectively. (h) Mean adipocyte size in inguinal fat in females. $n=9,16,8,11,7$ and 7 for female Veh, female CS, OVX Veh, OVX CS, OVX+DHT Veh and OVX+DHT CS mice, respectively. Results are shown as mean \pm SEM. $* p<0.05$, $* * p<0.01$, $*_{* *}^{*} p<0.001$, as indicated; ${ }^{\dagger \dagger} p<0.01,{ }^{\dagger \dagger} p<0.001$ vs female Veh

Our finding that, in female mice, corticosteroneinduced metabolic dysfunction also required androgens, has implications for polycystic ovary syndrome (PCOS). PCOS is a multifaceted endocrine disorder that affects 5 $17 \%$ of women of reproductive age, and is associated with both metabolic dysfunction and hyperandrogenism [43]. In women with and without PCOS, hyperandrogenism is associated with metabolic dysfunction [44, 45], and in a mouse model of PCOS, low-dose DHT treatment led to impaired glucose tolerance, hepatic insulin resistance and induction of hepatic gluconeogenesis [38]. Notably, in women with PCOS, anti-androgen treatment produced comparable effects to metformin in reducing fasting 

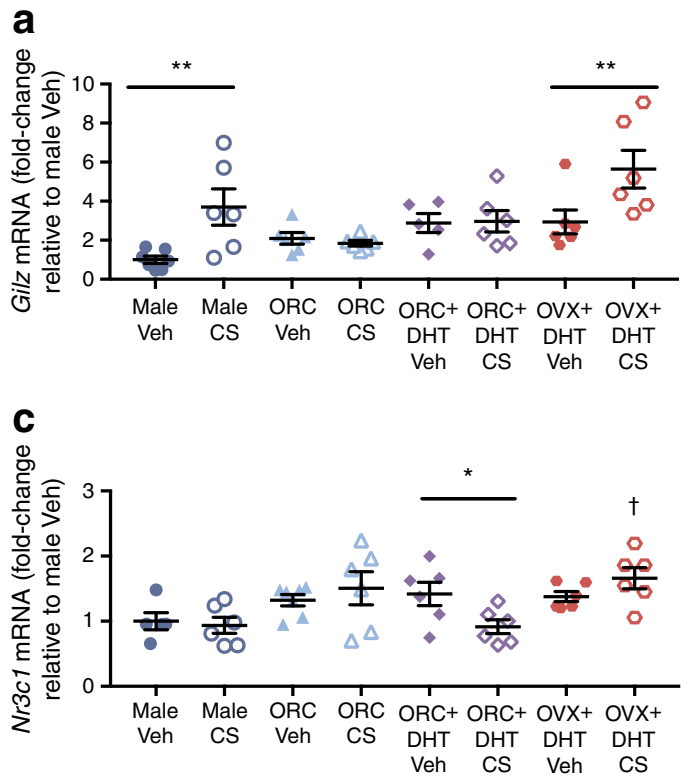

Fig. 8 Androgens sensitise adipose tissue to the transcriptional effects of glucocorticoids. (a) Gonadal WAT expression of Gilz mRNA (normalised to $18 \mathrm{~S}$ mRNA and shown as fold-change, relative to male Veh group). $n=6$ for all groups except male Veh $(n=7)$ and ORC+DHT Veh $(n=5)$. (b) Gonadal WAT expression of $A r$ mRNA. $n=6$ for all groups except

insulinaemia and glucose-stimulated insulin secretion [46]. Further studies investigating the androgenenhanced glucocorticoid signalling in PCOS aetiology are certainly warranted.

A secondary finding of this study was that female sex hormones also exerted some beneficial effects on the metabolic phenotypes studied. OVX mice typically gain more weight than intact females [47], and oestrogen treatment protects male mice against the metabolic consequences of obesity [48]. Overexpression of aromatase, which converts testosterone to oestrogen, selectively in WAT and BAT of mice improves insulin sensitivity, reduces body weight and relieves WAT inflammation [49]. The salutary effects of oestrogens on cholesterol metabolism and cardiovascular risk are well supported by human studies [50].

In conclusion, by identifying a striking sexual dimorphism in the metabolic effects of chronic glucocorticoid treatment in mice, we have shown for the first time that androgens are required for insulin resistance, hyperinsulinaemia, fat accumulation and whitening of BAT following chronic corticosterone exposure. DHT also potently stimulated lipid accumulation in WAT. The sensitising action of androgens for glucocorticoid responses not only has implications for the treatment of inflammatory or autoimmune diseases, but also for conditions characterised by hyperandrogenism, such as PCOS. Finally, this study highlights the importance of performing metabolic studies in both male and female mice, due to intrinsic differences in the regulation of energy balance between sexes. b
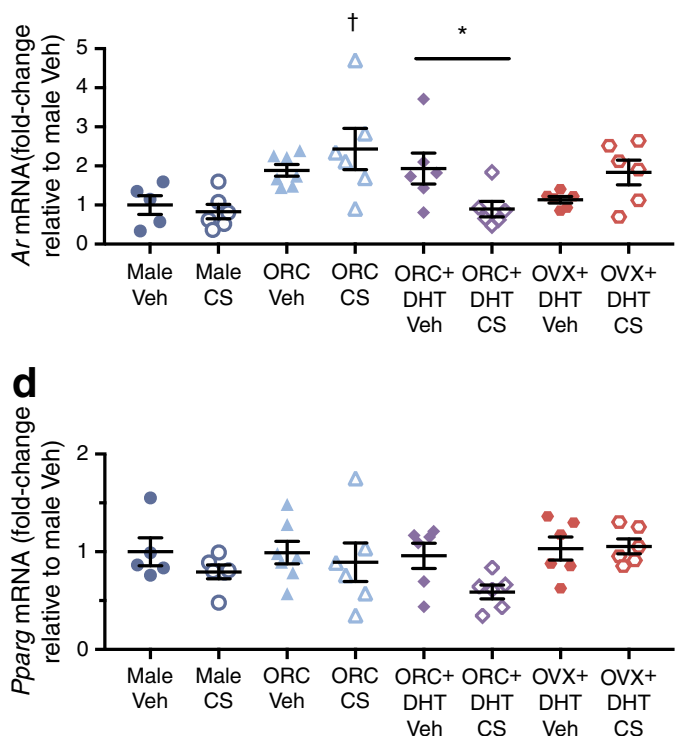

male Veh $(n=5)$ and ORC Veh $(n=7)$. (c) Gonadal WAT expression of $\mathrm{Nr} 3 \mathrm{cl}$ mRNA. Sample sizes as in (b). (d) Gonadal WAT expression of Pparg mRNA. Sample sizes as in (b). Results are shown as mean \pm SEM. $* p<0.05, * * p<0.01$, as indicated; ${ }^{\dagger} p<0.05$ vs male Veh

Acknowledgements We would like to thank M. S. Cooper and D. Handelsman (ANZAC Research Institute, The University of Sydney, Australia) for thoughtful discussion and comments throughout this project. We thank M. Jiminez (ANZAC Research Institute) for providing the DHT implants, and J. Spaliviero (ANZAC Research Institute) and E. Karsten (Kolling Institute, The University of Sydney, Australia) for their expert technical assistance. This work has not previously been published, but was included in the $\mathrm{PhD}$ thesis of SJG. Some of the results have been presented at local and international conferences.

Data availability All data presented in this manuscript is available on request from the authors.

Funding This study was supported by National Health and Medical Research Council (NHMRC) Project grant APP1086100 to MJS, MMS and HZ; the Australian government for Australian Postgraduate Award (SJG, SK); an International Postgraduate Research Scholarship (HH) and a research stipend from Humboldt University/ Charite University Medicine, Berlin (M-CW). The study sponsors were not involved in the design of the study; the collection, analysis and interpretation of data; writing the report; or the decision to submit the report for publication.

Duality of interest The authors declare that there is no duality of interest associated with this manuscript.

Contribution statement All authors have made substantial contributions to conception and design, acquisition of data or analysis and interpretation of data, drafting the article or revising it critically for important intellectual content, and have given final approval of the version to be published. SJG, MMS, HZ and MJS are guarantors of the work, accept full responsibility for the work and/or the conduct of the study, have access to the data, and controlled the decision to publish. 


\section{References}

1. Fardet L, Feve B (2014) Systemic glucocorticoid therapy: a review of its metabolic and cardiovascular adverse events. Drugs 74(15): 1731-1745. https://doi.org/10.1007/s40265-014-0282-9

2. Oray M, Abu Samra K, Ebrahimiadib N, Meese H, Foster CS (2016) Long-term side effects of glucocorticoids. Expert Opin Drug Saf 15(4):457-465. https://doi.org/10.1517/14740338.2016. 1140743

3. Arena C, Morin AS, Blanchon T et al (2010) Impact of glucocorticoid-induced adverse events on adherence in patients receiving long-term systemic glucocorticoid therapy. $\mathrm{Br} \mathrm{J}$ Dermatol 163(4):832-837. https://doi.org/10.1111/j.1365-2133. 2010.09877.x

4. Curtis JR, Westfall AO, Allison J et al (2006) Population-based assessment of adverse events associated with long-term glucocorticoid use. Arthritis Rheum 55(3):420-426. https://doi.org/10.1002/ art.21984

5. Ferrau F, Korbonits M (2015) Metabolic comorbidities in Cushing's syndrome. Eur J Endocrinol 173(4):M133-M157. https://doi.org/10.1530/EJE-15-0354

6. Cornier MA, Dabelea D, Hernandez TL et al (2008) The metabolic syndrome. Endocr Rev 29(7):777-822. https://doi.org/10.1210/er. 2008-0024

7. Grundy SM (1999) Hypertriglyceridemia, insulin resistance, and the metabolic syndrome. Am J Cardiol 83:25F-29F

8. Magomedova L, Cummins CL (2016) Glucocorticoids and metabolic control. Handb Exp Pharmacol 233:73-93

9. Rafacho A, Ortsater H, Nadal A, Quesada I (2014) Glucocorticoid treatment and endocrine pancreas function: implications for glucose homeostasis, insulin resistance and diabetes. J Endocrinol 223(3): R49-R62. https://doi.org/10.1530/JOE-14-0373

10. Macfarlane DP, Forbes S, Walker BR (2008) Glucocorticoids and fatty acid metabolism in humans: fuelling fat redistribution in the metabolic syndrome. J Endocrinol 197(2):189-204. https://doi.org/ 10.1677/JOE-08-0054

11. Palmer BF, Clegg DJ (2015) The sexual dimorphism of obesity. Mol Cell Endocrinol 402:113-119. https://doi.org/10.1016/j.mce. 2014.11.029

12. Strack AM, Bradbury MJ, Dallman MF (1995) Corticosterone decreases nonshivering thermogenesis and increases lipid storage in brown adipose tissue. Am J Phys 268:R183-R191

13. Thuzar M, Law WP, Ratnasingam J, Jang C, Dimeski G, Ho KKY (2018) Glucocorticoids suppress brown adipose tissue function in humans: a double-blind placebo-controlled study. Diabetes Obes Metab 20(4):840-848. https://doi.org/10.1111/dom.13157

14. Singh J, O'Neill C, Handelsman DJ (1995) Induction of spermatogenesis by androgens in gonadotropin-deficient (hpg) mice. Endocrinology 136(12):5311-5321. https://doi.org/10.1210/endo. 136.12.7588276

15. Gasparini SJ, Weber MC, Henneicke H, Kim S, Zhou H, Seibel MJ (2016) Continuous corticosterone delivery via the drinking water or pellet implantation: a comparative study in mice. Steroids 116:7682. https://doi.org/10.1016/j.steroids.2016.10.008

16. Brennan-Speranza TC, Henneicke H, Gasparini SJ et al (2012) Osteoblasts mediate the adverse effects of glucocorticoids on fuel metabolism. J Clin Invest 122(11):4172-4189. https://doi.org/10. 1172/JCI63377

17. Wright AS, Thomas LN, Douglas RC, Lazier CB, Rittmaster RS (1996) Relative potency of testosterone and dihydrotestosterone in preventing atrophy and apoptosis in the prostate of the castrated rat. J Clin Invest 98(11):2558-2563. https://doi.org/10.1172/ JCI119074

18. Shi X, Shi W, Li Q et al (2003) A glucocorticoid-induced leucinezipper protein, GILZ, inhibits adipogenesis of mesenchymal cells.
EMBO Rep 4(4):374-380. https://doi.org/10.1038/sj.embor. embor805

19. Nishizawa H, Shimomura I, Kishida K et al (2002) Androgens decrease plasma adiponectin, an insulin-sensitizing adipocyte-derived protein. Diabetes 51(9):2734-2741. https://doi.org/10.2337/ diabetes.51.9.2734

20. Jaussi R, Watson G, Paigen K (1992) Modulation of androgenresponsive gene expression by estrogen. Mol Cell Endocrinol 86(3):187-192. https://doi.org/10.1016/0303-7207(92)90143-T

21. Duma D, Collins JB, Chou JW, Cidlowski JA (2010) Sexually dimorphic actions of glucocorticoids provide a link to inflammatory diseases with gender differences in prevalence. Sci Signal 3:ra74

22. Spaanderman DCE, Nixon M, Buurstede JC et al (2018) Androgens modulate glucocorticoid receptor activity in adipose tissue and liver. J Endocrinol 240(1):51-63

23. Galpin KS, Henderson RG, James WP, Trayhurn P (1983) GDP binding to brown-adipose-tissue mitochondria of mice treated chronically with corticosterone. Biochem J 214(1):265-268. https://doi.org/10.1042/bj2140265

24. Shen Y, Roh HC, Kumari M, Rosen ED (2017) Adipocyte glucocorticoid receptor is important in lipolysis and insulin resistance due to exogenous steroids, but not insulin resistance caused by high fat feeding. Mol Metab 6(10):1150-1160. https://doi.org/10.1016/j. molmet.2017.06.013

25. Trayhurn P (1979) Fatty acid synthesis in vivo in brown adipose tissue, liver and white adipose tissue of the cold-acclimated rat. FEBS Lett 104(1):13-16. https://doi.org/10.1016/0014-5793(79) 81075-3

26. Muller TD, Lee SJ, Jastroch M et al (2013) p62 links betaadrenergic input to mitochondrial function and thermogenesis. J Clin Invest 123(1):469-478. https://doi.org/10.1172/JCI64209

27. Shimizu I, Aprahamian T, Kikuchi R et al (2014) Vascular rarefaction mediates whitening of brown fat in obesity. J Clin Invest 124(5):2099-2112. https://doi.org/10.1172/JCI71643

28. Kotzbeck P, Giordano A, Mondini E et al (2018) Brown adipose tissue whitening leads to brown adipocyte death and adipose tissue inflammation. J Lipid Res 59(5):784-794. https://doi.org/10.1194/ jlr.M079665

29. Rodriguez-Cuenca S, Pujol E, Justo R et al (2002) Sex-dependent thermogenesis, differences in mitochondrial morphology and function, and adrenergic response in brown adipose tissue. J Biol Chem 277(45):42958-42963. https://doi.org/10.1074/jbc.M207229200

30. Monjo M, Rodriguez AM, Palou A, Roca P (2003) Direct effects of testosterone, 17 beta-estradiol, and progesterone on adrenergic regulation in cultured brown adipocytes: potential mechanism for gender-dependent thermogenesis. Endocrinology 144(11):49234930. https://doi.org/10.1210/en.2003-0537

31. Cypess AM, Lehman S, Williams G et al (2009) Identification and importance of brown adipose tissue in adult humans. N Engl J Med 360(15):1509-1517. https://doi.org/10.1056/NEJMoa0810780

32. Choi DK, Oh TS, Choi JW et al (2011) Gender difference in proteome of brown adipose tissues between male and female rats exposed to a high fat diet. Cell Physiol Biochem 28(5):933-948. https://doi.org/10.1159/000335807

33. Mangelsdorf DJ, Thummel C, Beato M et al (1995) The nuclear receptor superfamily: the second decade. Cell 83(6):835-839. https://doi.org/10.1016/0092-8674(95)90199-X

34. Rundlett SE, Miesfeld RL (1995) Quantitative differences in androgen and glucocorticoid receptor DNA binding properties contribute to receptor-selective transcriptional regulation. Mol Cell Endocrinol 109(1):1-10. https://doi.org/10.1016/0303-7207(95)03477-O

35. Arora VK, Schenkein E, Murali R et al (2013) Glucocorticoid receptor confers resistance to antiandrogens by bypassing androgen receptor blockade. Cell 155(6):1309-1322. https://doi.org/10.1016/ j.cell.2013.11.012 
36. Cai C, He HH, Chen S et al (2011) Androgen receptor gene expression in prostate cancer is directly suppressed by the androgen receptor through recruitment of lysine-specific demethylase 1. Cancer Cell 20:457-471

37. Yu CY, Mayba O, Lee JV et al (2010) Genome-wide analysis of glucocorticoid receptor binding regions in adipocytes reveal gene network involved in triglyceride homeostasis. PLoS One 5(12): e15188. https://doi.org/10.1371/journal.pone.0015188

38. Andrisse S, Childress S, Ma Y et al (2017) Low-dose dihydrotestosterone drives metabolic dysfunction via cytosolic and nuclear hepatic androgen receptor mechanisms. Endocrinology 158(3): 531-544. https://doi.org/10.1210/en.2016-1553

39. Mehran AE, Templeman NM, Brigidi GS et al (2012) Hyperinsulinemia drives diet-induced obesity independently of brain insulin production. Cell Metab 16(6):723-737. https://doi. org/10.1016/j.cmet.2012.10.019

40. Protzek AO, Rezende LF, Costa-Junior JM et al (2016) Hyperinsulinemia caused by dexamethasone treatment is associated with reduced insulin clearance and lower hepatic activity of insulin-degrading enzyme. J Steroid Biochem Mol Biol 155:1-8. https://doi.org/10.1016/j.jsbmb.2015.09.020

41. Bauerle KT, Hutson I, Scheller EL, Harris CA (2018) Glucocorticoid receptor signaling is not required for in vivo adipogenesis. Endocrinology 159(5):2050-2061. https://doi.org/10. 1210/en.2018-00118

42. Bourke $\mathrm{CH}$, Raees MQ, Malviya S, Bradburn CA, Binder EB, Neigh GN (2013) Glucocorticoid sensitizers Bagl and Ppid are regulated by adolescent stress in a sex-dependent manner. Psychoneuroendocrinology 38(1):84-93. https://doi.org/10.1016/j. psyneuen.2012.05.001

43. Dumesic DA, Oberfield SE, Stener-Victorin E, Marshall JC, Laven JS, Legro RS (2015) Scientific statement on the diagnostic criteria, epidemiology, pathophysiology, and molecular genetics of polycystic ovary syndrome. Endocr Rev 36(5):487-525. https://doi.org/10. 1210/er.2015-1018
44. Korhonen S, Hippelainen M, Vanhala M, Heinonen S, Niskanen L (2003) The androgenic sex hormone profile is an essential feature of metabolic syndrome in premenopausal women: a controlled community-based study. Fertil Steril 79(6):1327-1334. https://doi. org/10.1016/S0015-0282(03)00347-9

45. Apridonidze T, Essah PA, Iuorno MJ, Nestler JE (2005) Prevalence and characteristics of the metabolic syndrome in women with polycystic ovary syndrome. J Clin Endocrinol Metab 90(4):1929-1935. https://doi.org/10.1210/jc.2004-1045

46. Ganie MA, Khurana ML, Nisar S et al (2013) Improved efficacy of low-dose spironolactone and metformin combination than either drug alone in the management of women with polycystic ovary syndrome (PCOS): a six-month, open-label randomized study. J Clin Endocrinol Metab 98(9):3599-3607. https://doi.org/10.1210/ jc. 2013-1040

47. Hong J, Stubbins RE, Smith RR, Harvey AE, Nunez NP (2009) Differential susceptibility to obesity between male, female and ovariectomized female mice. Nutr J 8(1):11. https://doi.org/10. 1186/1475-2891-8-11

48. Dakin RS, Walker BR, Seckl JR, Hadoke PW, Drake AJ (2015) Estrogens protect male mice from obesity complications and influence glucocorticoid metabolism. Int J Obes 39(10):1539-1547. https://doi.org/10.1038/ijo.2015.102

49. Ohlsson C, Hammarstedt A, Vandenput L et al (2017) Increased adipose tissue aromatase activity improves insulin sensitivity and reduces adipose tissue inflammation in male mice. Am J Physiol Endocrinol Metab 313(4):E450-E462. https://doi.org/10.1152/ ajpendo.00093.2017

50. Palmisano BT, Zhu L, Eckel RH, Stafford JM (2018) Sex differences in lipid and lipoprotein metabolism. Mol Metab 15:45-55. https://doi.org/10.1016/j.molmet.2018.05.008

Publisher's note Springer Nature remains neutral with regard to jurisdictional claims in published maps and institutional affiliations. 